Revista Iberoamericana, Vol. LXVII, Núm. 196, Julio-Setiembre 2001, 389-398

\title{
EL OTRO MODERNISMO: EL CASO DE DARÍO HERRERA
}

POR

IVAN SCHULMAN

University of Illinois

\author{
Hoy Panamá con el Canal acrece \\ El progreso del mundo, a quien ofrece \\ Toda la magnitud de su Océano...
}

Darío Herrera, Lejanías 97

Hace años ${ }^{1}$ aludimos a la existencia de unas genealogías secretas del modernismo, postulación revisionista formulada para modificar la predominante teoría monolítica que priorizaba ciertas características discursivas del modernismo —arte escapista, manía estilística, desaire de códigos sociopolíticos-conceptualizaciones exageradas e inexactas si no espejismos enunciados por la crítica tradicional con el fin de describir y justificar las a menudo inexistentes cadencias y sucesiones cronológicas y estilísticas de una compleja y heterogénea etapa de la historiografía literaria americana.

En dicha etapa, la del modernismo, las manifestaciones textuales son múltiples y heterológicas. Y, por lo tanto, es a nuestro juicio, imprescindible evadir la práctica tradicional de reducir el arte modernista a una serie de generalizaciones fundamentalmente esencialistas y generalmente de naturaleza exclusivamente ideológica, historiográfica, estética o estilística. Todo lo contrario, urge acentuar la diversidad, apertura e inestabilidad de las textualizaciones modernistas y la interconectividad entre éstas y las metamórficas instituciones sociopolíticas del mundo moderno. De hecho, lo que proponemos es la idea de la pluralidad modernista, concepto afín al de la(s) filosofía(s) existencialista(s), o sea el concepto de varios modernismos que dejaron sus huellas no sólo en las producciones de una literatura elitista sino en espacios diversos de la cultura popular.

Una de las consecuencias de no operar con un sistema analítico basado en la heterogeneidad es la tendencia a perfilar y perpetuar un modernismo homogéneo y, por ende, distorsionado. Otra de sus consecuencias es la desafortunada exclusión del canon de figuras y obras, primordialmente de literaturas pertencientes a regiones o países situados al margen del proceso desarrollista del capitalismo iniciado en América a partir de la segunda mitad del siglo diecinueve, proceso modernizador, iniciación de la globalización socioeconómica y cultural, comentado por muchos modernistas en textos normalmente

\footnotetext{
${ }^{1}$ En una conferencia magistral dictada en 1985 en una sesión del congreso sobre prosa de la vanguardia organizado por Fernando Burgos en la Universidad de Memphis (Tennessee, EUA).
} 
excluidos de las antologías y ediciones de esta literatura. ${ }^{2}$ ¿En cuántas de estas recopilaciones encontramos textos de la producción de Costa Rica, de Guatemala, del Ecuador o de Panamá? ¿En cuántas abundan las voces de aguda alarma y de alienación características de los textos sociales y políticos del período-poemas, crónicas, ensayos. Y, ya que de omisiones canónicas hablamos, ¿en cuántas hay textos en prosa y verso de mujeres cuya obra dispersa en periódicos y revistas queda todavía por rescatar?

Con el fin de iniciar el rescate imprescindible de textos y figuras del modernismo, exploraremos la obra de tres figuras modernistas consignadas por distintas razones a los distanciados espacios fronterizos del discurso crítico que han sufrido inmerecidas distorsiones en la historia literaria canónica. Me refiero a Juana Borrero de Cuba, Rafael Angel Troyo, de Costa Rica, y Darío Herrera, de Panamá.

LA ESCRITURA DE UNA MUJER: JUANA BORRERO

Amiga, y según algunos, discípula de Julián del Casal, la biografía de Juana Borrero ha ocupado más a los críticos que su obra de creación. Tal enfoque no es nada atípico en el discurso patriarcal tratándose de una mujer/escritora, pues similar ha sido el caso de su compatriota, Gertrudis Gómez de Avellaneda. Pero a la luz de la narración revisionista del modernismo, más significativo nos parece estudiar cómo y en qué medida su discurso poético se inserta en el del modernismo hispanoamericano, buscando en su arte no los nexos entre vida y verso sino la voz del sujeto fin de siècle, la del artista atormentado y aislado, víctima de las incertidumbres del mundo moderno; el ser asediado por los cuatro estigmas descritos por su contemporáneo, José Martí: "la Intranquilidad, la Inseguridad, la Vaga Esperanza, la Visión Secreta” (VII 229), en fin, la escritora hostigada por “lo desconocido, eco de lo sobrenatural, espejo de las luces eternas, copia más o menos acabada del mundo en que vive" (VII 229), todo lo cual se transparenta en el discurso de ella y es la nota característica del artista de la incipiente modernidad social y cultural de América. Sin embargo, un artista tan perspicaz como Darío, al comentar la obra de Borrero parte de premisas patriarcales cuyo primer signo referido a la poeta es la equiparación de su persona artística con lo "virginal” y lo "misterioso"; la llama "extraña virgen hoy difunta" (Poesías 175). Pero antes de formular la loa de la "extraña virgen”, en el mismo ensayo, marcó el

${ }^{2}$ Las historias del modernismo han tratado de ser más inclusivistas, debido quizá al hecho de que la narración del canon de la literatura hispanoamericana nunca ha prestado atención a la admonición de Alfonso Reyes de que "el fárrago es lo que nos mata" (concepto que expresó en su ensayo "Valor de la literatura hispanoamericana” (76). De ahí las enumeraciones casi infinitas y exhaustivas que descubrimos en tantas historias de la literatura americana, verdaderos "catálogos de semilla para pájaros” según el comentario irónico de hace años de Isaac Goldberg. Y, en la historia clásica del modernismo, la de Max Henríquez Ureña, Breve historia del modernismo hay un ejemplo admirable del inclusivismo a que hemos aludido, un ejemplo, por otra parte, admirable, pues el crítico dominicano conoció personalmente a muchas figuras del modernismo. Las antologías, sin embargo han tendido a ser no sólo exclusivistas sino a revelar una incapacidad casi ingénita por ajustar la selección de los textos a las evoluciones del discurso crítico. O en otras palabras, han seguido la ruta tradicional del antirrevisionismo. En Poesía modernista hispanoamericana y española los antologistas han hecho un esfuerzo por ampliar el canon de la poesía y de incluir la producción de países que suelen no figurar en la mayoría de las antologías—el caso, por ejemplo, de Puerto Rico. 
terreno de las diferencias genéricas referidas a la creación artística al acudir a metáforas entresacadas de la naturaleza para caracterizar a la mujer y a su capacidad creadora, enraizada ésta en conceptos alusivos a la reproducción y la fertilidad: “es de llorar —escribió Darío- con gran desolación por esas desaparecidas flores que se creerían imposibles entre la común vegetación femenina (énfasis nuestro; Poesías 177). Y en el mismo venero el nicaragüense formula las siguientes generalizaciones sobre lo femenino:

Esas almas femeninas tienen en sí una a manera de naturaleza angélica que en ocasiones se demuestra con manifestaciones visibles; son iguales en lo íntimo a los hombres elegidos del ensueño, y se elevan tanto más maravillosamente cuanto sus compañeras terrenales, inconscientes, uterinas, o instrumentos de las potencias ocultas del mal, son los principales enemigos de todo soñador (Poesías 177).

Pese a las alabanzas que hace Darío del vuelo poético de Borrero, los conceptos que expresa sobre el tema de las mujeres y las escritoras no constituyen una excepción de la ideología hegemónica de aquella época, sino una norma, como lo demuestra la siguiente enunciación entresacada de una entrega de la revista El mundo del arte de 1894:

Una mujer excesivamente ilustrada es tan peligrosa como la mujer ignorante, porque la excesiva ilustración, como la ignorancia inicial la separan de su grande arte, que es el sentimiento, de su gran ciencia, que es el hombre, de su segunda religión que es el hijo (Saporta 40).

Juana Borrero fue una mujer ilustrada y de un talento artístico nada común. La re/ lectura contemporánea y cuidadosa de sus textos revela cierta tensión entre la distancia sicológica, la frialdad, la línea esculpida y el filón instrospectivo, la queja personal, la expresión del hastío, signos ineludibles del poeta moderno, del poeta, según Martí que “ya no ve en sus ojos las estrellas del cielo, [y] los vuelve a las de su alma” (VII 224). Entre sus composiciones modernistas —agónicas como las de Darío, Martí, o Silva— encontramos las que interrogan al cielo, a Dios, en busca prototípica de las contestaciones y aclaraciones que nunca reciben los poetas modernistas asediados por la fe perdida. En su afán por captar imágenes de lo interior se sirve de visiones exteriores estructuradas en forma característica del discurso modernista: es decir, mediante metaforizaciones que signan la visión maniqueísta del mundo, expresión de la lucha entre la vigilia y el sueño. La nota disconforme de quejas y congojas se amplía en el caso de Borrero de una manera similar a la de otros modernistas, con resonancias relacionadas con el discurso social y político —-nexo que sólo recientemente se ha logrado incorporar al discurso crítico sobre los textos de los modernistas hispanoamericanos. En su poema "El Ideal” Borrero alude al tema de la nación, a la patria, que dice que "siempre irá conmigo” y que “me dará ardor ante el obstáculo” (62-3). Y, en "Esperad” (68), poema de innegable timbre modernista, se transparenta con nítida especificidad el deseo de la libertad patria y el sentimiento de culpabilidad experimentado por seres pasivos ante la represión. En estos y otros versos se transparenta un "gemir" asociado con la oposición política, y la administración española de la isla. Su lectura recuerda el tono y la intensión de “Sueño con claustros de mármol” (Versos libres) de Martí, y en ellos se transparenta la asfixia que Borrero experimentó en el limitado recinto paterno. 
La independencia de su ser, su aspiración a la libertad creadora se suma al deseo de la libertad patria. El perfume de la lírica íntima, el amor como patria se entrelazan con la política separatista del padre, y generan versos modernistas de horizontes contemplados desde la orilla interior.

\section{La estrategia Del Revés: Rafael Angel Troyo}

La crítica, mínima e insuficiente, en torno a Rafael Angel Troyo, ha preferido examinar y comentar las texturas y apariencias de su obra desde el ángulo del costumbrismo y del nacionalismo tradicionales. Pero frente a la "preceptiva” costumbrista de una sociedad burguesa y pacata, Troyo y otros artistas como Ricardo Fernández Guardia, Ernesto Martén y Alejandro Alvarado Quirós, que no eran anti-nacionalistas, defendieron el principio de la libertad del artista, quien, según Fernández Guardia "tiene un temperamento especial, que lo lleva con fuerza irresistible hacia determinados ideales” (Mosquera de Martínez, "Polémica..." 292). Los nacionalistas rechazaron las innovaciones, rupturas, invenciones y experimentos del estilo moderno; repudiaron lo que Darío llamó el movimiento de libertad artística. Y los "liberales" - los modernistas en Costa Rica- buscaban innovar frente a la modernidad burguesa que anhelaban reemplazar con una modernidad estética, alternativa. En resumidas cuentas reaccionaron en contra de la soledad espiritual, el tedio, la esterilidad artística y la chabacanería del progreso material.

Troyo, autor de seis libros de prosa, ${ }^{3}$ prefería evocar los paisajes gélidos, estériles, blancos, sugeridores de la muerte, la tragedia o la tristeza — como Darío Herrera. Y estos paisajes los alternaba con sus opuestos: los risueños, diáfanos, levemente melancólicos y azules, portadores de la dicha ensoñada, aunque fugaz. Es frecuente que aparezcan ambos paisajes o espacios poéticos en la misma prosa breve; su presencia en construcciones contrapuestas, enunciaciones del revés, simbolizaba la lucha y/o la alternancia de las fuerzas vitales de la existencia con el sino mayormente sombrío del hombre moderno. O en otros textos, el concepto del revés se manifiesta con las características del cuadro parnasiano o de la miniatura decorativa. En tales formulaciones se verifica el desplazamiento del universo material hacia la contemplación de los objetos de belleza y lujo del Segundo Imperio, reunidos a veces bajo el signo de la cultura oriental (como en "Marfil” de Terracotas).

La percepción y creación de la “otra” realidad y la técnica del contraste, ambos recursos iterados y recurrentes en la obra de Troyo, están ligados a la inestabilidad metafísica, la inseguridad sociocultural, el desequilibrio temible de la sociedad en trance de modernizarse. El artista, con su sensibilidad ofendida por el materialismo reinante, testigo y víctima de esta transformación, percibirá en el ambiente que lo rodea un malestar general cuya existencia no textualiza en términos nacionales, sino en un espacio más bien universal. Y frente a este malestar, aislado y/o marginado por él, construirá otra realidad que no es, a nuestro modo de ver, el signo de un discurso torreburneista, sino un modo de ocultarse sin huir de la realidad, una forma de "replantear la batalla en otro terreno" (Vitier 297). De ahí, como en Ricardo Jaimes Freyre, en conformidad con una ingénita tristeza, la visión de una realidad

\footnotetext{
${ }^{3}$ Terracotas, 1900; Ortos, 1903; Corazón joven, 1904; Poemas del alma, 1906; Topacios, 1906;
} Ortos, 1907. 
contrapuntal ceñida casi exclusivamente a la estepa, la nieve, el blanco. Hay, además en su obra un aire de desquiciamiento, el de un universo que ha perdido su norte y, descentrado, gira vertiginosamente con penosa decadencia hacia fronteras no conocidas sino apocalípticas. Es, en el fondo, una literatura de valores invertidos, inesperados y hasta transgredidos, de un código sociocultural que corresponde a un mundo en crisis, carente de base racional. Es la escritura del revés, concebida desde la dinámica contrapuntal —una segunda realidad cuyos objetos a veces se insertan en un discurso de valores idealizados. Y, sin embargo, al mismo tiempo, como en la obra de Darío Herrera, se descubre una constante preocupación por el ser humano, por el hambre y la pobreza, por el individuo enfermo, solo, ciego, inválido, huérfano o desamparado. Le atormentan a Troyo el desconsuelo del amante, las separaciones, el amor no correspondido, los trágicos desenlaces sentimentales. Troyo comprendió los signos negativos de su época — los de la vida moderna primigenia—, y frente a las disyuntivas creadas por ella, buscó “armar su batalla” en otros terrenos mediante la estrategia del revés.

DARÍo HERRERA: UN ESCRITOR IGNORADO

Así caracteriza Rodrigo Miró a Darío Herrera (Horas lejanas y otros cuentos 5) en dos ocasiones y, en una de ellas se refiere a Herrera como el escritor inexistente para los panameños. ${ }^{4}$ De ser así su lugar en la literatura nacional de Panamá, no debe ser motivo de sorpresa que sea una figura desconocida en el resto de América y un escritor excluido del canon de la literatura modernista. Yo recuerdo haber escuchado su nombre por primera vez como alumno de posgrado en la Universidad de California, en un curso sobre el modernismo hispanoamericano que impartió Max Henríquez-Ureña, profesor visitante durante un verano en esa universidad. Pedro Henríquez-Ureña, quien trató mucho a Herrera y lo ayudó en La Habana cuando Herrera tuvo que internarse en un sanatorio para curar uno de sus muchos ataques de neurosis, no se detuvo en el análisis de la obra del escritor panameño, ni insistió en la lectura de sus textos. Más tarde, en la misma Universidad de California Manuel Pedro González, en el momento en que iniciamos la revisión de la cronología modernista —entre 1956 y 57- me indicó la importancia de una enunciación crítica de Darío Herrera, lector dedicado de la literatura contemporánea y conocedor profundo de los textos de los modernistas americanos. Decía Herrera:

Para mí Darío y Casal han sido los propagadores del Modernismo, pero no los iniciadores. Este título corresponde más propiamente a José Martí y a Manuel Gutiérrez Nájera ... ${ }^{5}$

Estas palabras de Herrera escritas en 1895, prefiguran la revisión de la historia de la literatura modernista. Pero desgraciadamente no contribuyeron a reorientar a los estudiosos

\footnotetext{
${ }^{4}$ En el prólogo a Horas lejanas y otros cuentos dice “....Herrera es hoy un escritor ignorado” (5), y en “Darío Herrera en el centenario de su nacimiento” insiste de manera tajante sobre esta caracterización: “”’Darío Herrera [es] la figura más conspicua del Modernismo en Panamá...No obstante ello, escritor inexistente para la mayoría de los panameños” (11; el énfasis es mío).

${ }^{5}$ Se trata de un artículo publicado en Panamá en 1895 que Gloria Luz Mosquera de Martínez cita en su libro sobre Herrera (100).
} 
del modernismo en las primeras décadas del siglo XX. Todo lo contrario. Quedaron sepultadas - lo mismo que su prosa y verso — hasta que varios investigadores iniciaron el proceso de rectificar el concepto del modernismo y el proceso de su evolución. Y hasta ese momento — segunda mitad del siglo XX — las palabras de Herrera junto con sus textos y los de otros creadores del período, formaron parte de lo que hoy en día podríamos denominar la historia del modernismo sin historia. ${ }^{6}$

No formaron parte de la historia literaria, por ejemplo, los textos de Herrera que revelan una capacidad descriptiva comparable en intensidad creadora y maestría descriptiva con la labor acualerista de figuras del modernismo como José Asunción Silva o Rubén Darío. Pensamos en la conclusión de unas impresiones de viaje, género cultivado mucho por Herrera, en que el panameño pinta un paisaje visto desde un barco anclado en Punta Arenas, Chile (1904):

\begin{abstract}
La tarde declina. El vapor traza su última curva y entra en un ensanche del estrecho. Las orillas se dilatan: un vasto lago reemplaza los canales. Más serena, más cerúlea, el agua parece dormir un divino sueño de hermosura. El sol viaja ya detrás de las cumbres, las penumbras vespertinas empalidecen la nieve; fundidas en una sola, las dos costas cierran el horizonte dentro de un círculo hermético. Así los Andes, siempre soberbios, ahora de nuevo lejanos, con sus moles blancas, escalonadas en colosal gradería, traen a la mente la idea de un portentoso coliseo tallado en mármol por la naturaleza creadora para luchas de cíclopes y dioses [...] (Horas lejanas y otros cuentos 214)
\end{abstract}

En éste y otros textos de Herrera abundan los vocablos y las imágenes referentes a movimiento, desplazamientos, viajes, contactos humanos furtivos, en fin, las separaciones y lejanías típicas de los textos de Herrera, las que se enlazan con el discurso modernista, o de los registros de él en que se refracta un sentimiento colectivo de enajenamiento a nivel íntimo y a nivel social. La imaginería glacial y la del distanciamiento traen a la memoria el metaforismo paralelo de Casal en el cual Cintio Vitier descubre un soterrado sentimiento de vacío generado por el cerrado ambiente colonial de La Habana. De Herrera, sin que se trate necesariamente de un una causa idéntica, descubrimos, tanto en su prosa como en sus versos, una imaginería paralela de tardes distantes, de una “atmósfera glacial” captadas entre ”presagios de amarguras” con figuras pálidas, níveas e inmóvibles” (Lejanías 25, 26, 28). ¿Responde este metaforismo a un deseo de fugarse de una realidad nacional?; ¿revela una preferencia por los escenarios extraños, distantes?; o es que, como en el caso de otros modernistas —Darío, Casal, Rebolledo, Tablada—, debemos buscar por debajo de las palabras del discurso un significado más profundo, un significado que sugiere un replanteamiento de la lucha contra el materialismo y las estrecheces de la vida nacional en sus incipientes etapas de la modernización burguesa. Para llegar al plano de la realidad de este metaforismo de Herrera, no nos satisface, sobre todo a la luz de las revisadas conceptualizaciones en torno al modernismo americano, la crítica inspirada en un concepto estrecho del nacionalismo. No nos parece acertado sugerir que debido al hecho de que sus

\footnotetext{
${ }^{6}$ Apropio el término que Juan Pérez de la Riva dio a la gente sin historia en Cuba —negros y chinos— en la historiografía mutilada y astigmática del proceso de la formación de la nación. Ver por ejemplo su libro: El barracón y otros ensayos.
} 
cuentos “están impregnados de exotismo, [...] [que] quizá por esto y por su poca intervención en los asuntos políticos del Istmo se ha llegado a decir que es el escritor 'menos panameño' que tiene la historia de Panamá” (Mosquera 100-101). Creo que, como en el caso de Rafael Angel Troyo, en el de Herrera tenemos que superar la tendencia tradicional de medir la calidad de la obra de los escritores en términos de una metonomia discursiva de raíz nacional. Y menos en un escritor que con ternura y afecto en una carta destinada a su amigo Rubén Darío alude a "Mi Panamá”, y luego agrega:

[...] cual Ud. bien lo sabe, lo mismo cuando estaba unida a Colombia que ahora, [Panamá] ha tenido siempre, por su situación geográfica, modalidad especial, y la ciudad capitalina más parecida es a pequeñas ciudades de los EE.UU. i (sic) francesas que a los que componen la República de Colombia” (Mosquera 109).

Y qué decir de poemas como “Colón”, “Balboa”, “Ayacucho” y “Canal” en cuyos versos se evidencia el amor por "el esplendor oceánico” de su patria (“Balboa”) y la entrañable pasión de Herrera por el continente americano (Lejanías 94-7). ${ }^{7}$

Pero, no es por revelar su obra un nexo con la nación en formación, ni por la presencia en su escritura de códigos nacionales que insistimos en la inserción de Herrera en el canon modernista. No. Es que descubrimos en sus textos a un artista consumado, a un poeta en prosa que, por ejemplo, supo describir con la técnica de un pintor las llamas de paisajes que

[...] adquirían las más caprichosas figuras, y se diseminaban, radiantes, por la atmósfera incendiada. Sobre la extremidad izquierda de la línea de occidente, un castillo de ónix, del período medioeval...amplio lago violeta, ceñido por playas de oro (Horas lejanas y otros cuentos 17).

Parecería que estas y otras descripciones análogas, las que abundan en la prosa de Herrera, son de carácter fundamentalmente metonímicas. Sin embargo, su iteración continua sugiere valores metafóricos referentes al escrutinio de los espacios en busca de horizontes alternativos, de otros mundos, más en armonía con las ansiedades y los anhelos del escritor modernista. Es el caso de los horizontes registrados por Julián del Casal en los sonetos de "Mi Museo Ideal”. Y es el caso, a nuestro juicio de las crónicas de viaje, de los cuentos, y hasta de algunos de los versos de Herrera. De hecho, en un poema titulado "Visionaria” la joven soñadora frente a la "jovial y fresca aurora” que "su luminosa púrpura descoge en el jardín” intenta visionar lo que existe más allá de la realidad concreta; pero desgraciadamente sólo logra percibir los "ritmos” y las rimas de una “pálida visión”. Curiosamente, Herrera inicia los versos con la cita de unos versos de Julián del Casal. La figura de la mujer es estática, diríase glacial; su buceo epistemológico, en esencia frustrado, sugiere una dimensión paralela del discurso del poeta, el del tedio o de la penumbra nacidos de la frustración, del sentimiento del vacío espiritual que experimentan los personajes o los

\footnotetext{
${ }^{7}$ En prosa, “Nuevas savias” alude al canal: “ Pero la canalización prosigue con pasmosa rapidez, anulando todos los obstáculos de la tierra abrupta. Y puede tenerse ya fe en el no distante, magno consorcio de los océanos" (Horas lejanas y otros cuentos 219).
} 
hablantes de sus creaciones. Un presentimiento de derrumbe informa sus creaciones y, como en los textos de Lugones, se asocia con una inevitable ruptura del enlace amoroso: “Íbamos visitando en el vacío./ Templos de nuestro amor dichas pasadas,/ Vimos aparecer en las miradas/ Un pálido crepúsculo de hastío...” (“Instantes” en Lejanías 67). El vacío de la experiencia humana, su carácter enigmático y triste, representan, en un plano metafórico, la periférica posición existencial de los creadores modernistas. Una visión antihegemónica y contracultural es la que se transparenta, por ejemplo, en "el lila desfalleciente", de "las ruinas de un palacio corintio", con "grandes témpanos de hielo" ("Meditación en Horas lejanas y otros cuentos 83) que se perciben en el horizonte distante captado por el angustiado poeta/creador de Panamá.

Las enunciaciones contraculturales asociadas con el inconformismo frente a los materialismos del proceso de la modernización burguesa son de índole variada pero con algunos paralelismos notables con Darío o Martí. En los textos de Herrera se evidencian en observaciones como la siguiente de naturaleza síquico-personal en que los conceptos antifeministas que planteamos, en relación con la obra de Borrero, operan en el ámbito de las costumbres y de la vida familiar:

La civilización ha roto el molde psíquico de la mujer antigua; hoy le es preciso ser la ayuda eficaz del hombre en la lucha por la vida, hasta donde pueda abarcar su imperfecta mentalidad. [...] El modernismo de la esposa consistía en una permanencia continua fuera de su casa, en ocupaciones frívolas [...] (Lejanías 105)

$\mathrm{O}$, en apreciaciones abiertamente antimodernas, es decir antiutilitarias generadas por el ejemplo de la cultura norteamericana:

Me abruman —a mí, latino por esencia— sus maquinarias, sus puentes, sus edificios, sus diarios, sus réclames, todas sus creaciones enormes y desproporcionadas: ellas evidencian un don especial para lo inarmónico, para lo inartístico. (Lejanías 43)

Los artistas del modernismo, frente al materialismo que empezaba a caracterizar las sociedades hispanoamericanas de fin de siglo, optaron por los desplazamientos espaciales y lingüísticos de signo estético. Apropiaron elementos de otras culturas, se situaron en otros climas, pero no necesariamente para dar la espalda a su realidad, sino más bien como estrategia de disconformidad, y con el fin de re-constituir su mundo desde una modernidad alternativa, distinta de la del capitalismo en formación de la época. En la obra de Herrera, ¿cómo se tranparenta esta posición contracultural?. Pues, en los infinitos poemas de prosa insertados en sus cuentos y crónicas, en el escrutinio de los horizontes, en la captación de visiones de otros mundos vistos a través del hipnotismo o de estados de ánimo considerados socialmente anormales, en metaforizaciones expresionistas similares a las que abundan en la obra de Julio Herrera y Reissig, o de Leopoldo Lugones, las que en un plano de realidad ensoñada reorganizan el mundo. Nos referimos a construcciones como "la tarde [que] se adormece en la llanura”, el horizonte “que distante/Describe su parábola azulina”, (Lejanías

${ }^{8}$ A continuación agrega: "Pero, en cambio, poseen algo encantador, algo de que guarda mi espíritu un recuerdo imborrable. ¡Ah, sus mujeres!” (43) 
63). O las escultóricas creaciones parnasianas y clásicas inspiradas en apropiadas fuentes mitológicas del mundo grecolatino, las que Herrera inserta en los siguientes versos del poema "Báquico” del “Grupo escultórico”:

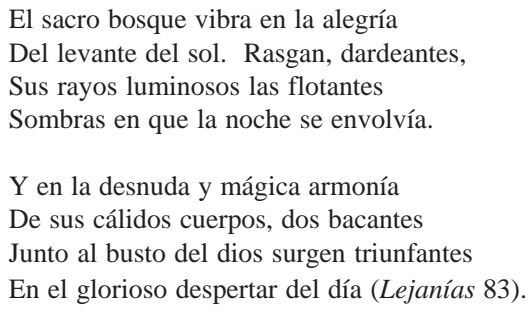

Hay, además, en la obra de Herrera intertexualidades discursivas que contextualizan sus creaciones en el ámbito literario hispanoamericano; relacionan su arte con el de figuras consagradas del canon como Herrera y Reissig, José Asunción Silva o Leopoldo Lugones. El arte de su prosa y verso impone la necesidad de revisionar su producción en forma sistemática y completa, revisión que situará al modernista panameño en el lugar que merece en el canon del modernismo, revisión que lo sacará—a él y a otras figuras del modernismo panameño — como Salomón Ponce Aguilera, Guillermo Andreve o Ricardo Miró— del injusto olvido no sólo en los anales de la literatura panameña sino en la historia de las letras del continente americano.

\section{BibliogRAFÍA}

Borrero, Juana. Poesías. La Habana: Instituto de Literatura y Lingüística, 1966.

Darío, Rubén. Obras completas. V. Madrid: Aguado, 1953.

Del Casal, Julián. Obra poética. La Habana: Editorial Letras Cubanas, 1982.

Henríquez-Ureña, Max. Breve historia del modernismo. 2a ed. México: Fondo de Cultura Económica, 1962.

Herrera, Darío. Horas lejanas y otros cuentos. Panamá: Ediciones de la Lotería Nacional de Beneficencia, 1971.

Lejanías. Panamá: s.i., 1971.

Martí, José. Obras Completas. La Habana, Editorial Nacional: 1963.

"Prólogo al Poema del Niágara”. Obras completas. VII. La Habana: Editorial Nacional, 1963-73. 221-38.

Miró, Rodrigo. Horas lejanas y otros cuentos. Prólogo. Panamá: Ediciones de la Lotería Nacional de Beneficencia, 1971. 5-8.

"Darío Herrera en el centenario de su nacimiento". Boletín de la Academica Panameña de La Lengua, 3a época (octubre 1970): 11-24.

Mosquera de Martínez, Gloria Luz. Darío Herrera, modernista panameño. Madrid: Imprenta Aguirre, 1964.

“Polémica entre nacionalismo y literatura”. Letras 8-9 (Heredia, Costa Rica, 19811982): 292. 
Reyes, Alfonso. Páginas escogidas. La Habana: Casa de las Américas, 1978.

Saporta Sternbach, Nancy. "The death of a beautiful woman: modernismo, the woman writer and the pornographic imagination”. Ideologies and Literature (Spring, 1988): 35-60.

Schulman, Ivan A. "Las genealogías secretas de la narrativa: del modernismo a la vanguardia”. Prosa de vanguardia hispánica. Madrid: Orígenes, 1986. 29-41. y Evelyn Picon Garfield, eds. Poesía modernista hispanoamericana y española. 2a. edición. San Juan: Editorial de la Universidad de Puerto Rico, 1999.

Troyo, Rafael, Ángel. Topacios. San José: Imprenta Alsina, 1907. Poema del alma. San José Imprenta Alsina, 1906. Corazón joven. San José: Establecimiento Tipográfico de A. Alsina, 1904. Ortos. San José: Imprenta de A. Alsina, 1903. Terracotas. San José: Imprenta Lines, 1900.

Vitier, Cintio. Lo cubano en la poesía. La Habana: Instituto del Libro, 1970. 